\title{
GROWING WHITEFISH FINGERLINGS IN REARING PONDS
}

WEN K. LIAW, Saskatchewan Fisheries Laboratory, Department of Tourism and Renewable Resources, 30 Campus Drive, Saskatoon, Saskatchewan. S7N 0X1

Being the mainstay of commercial fish production, whitefish is one of the most economically important fishes in Saskatchewan. The commercial fishermen (now about 14 hundred in total) harvested about 2.3 million $\mathrm{kg}$ of whitefish annually from some 200 lakes over the past four decades. However, production has dropped considerably in recent years. The current annual harvest is about 1.7 million $\mathrm{kg}$.

Overfishing and habitat deterioration appear to have severely affected the whitefish stocks in a number of lakes; in some, the fishery has virtually collapsed.

In order to find a better way to restore a collapsed fishery and to enhance a declining fish population, the Fisheries Branch recently carried out a pilot project of growing whitefish in rearing ponds for later release into problem lakes. The immediate objective of the project was to determine the growth and production of whitefish fingerlings in the rearing ponds. This article summarizes the findings of the study.

\section{The Rearing Ponds}

Figure 1 shows the location of the three lakes that were used as rearing ponds in 1981 and 1982 (only one pond was used in the second year). The ponds varied from 2.4 to 225 ha in area and 1.4 to $1.8 \mathrm{~m}$ in mean depth.

Turtle Lake Pond, located on a sheep ranch, was more fertile than the two northern ponds which drain a forestmuskeg watershed. The biomass of bottom organisms (an important food source for fingerlings) was an order-of- magnitude more abundant in Turtle Lake Pond than in the two northern ponds.

Surface water temperatures for all three ponds from June to August ranged from 13 to $21^{\circ} \mathrm{C}$ with an overall average of $18^{\circ} \mathrm{C}$.

Fathead Minnows and Brook Sticklebacks were very abundant in McMahon Pond and Brook Sticklebacks in Kallemeyn Pond. However, the stickleback population in Kallemeyn Pond was reduced considerably in 1982 due to winterkill. Native fish were not found in Turtle Lake Pond.

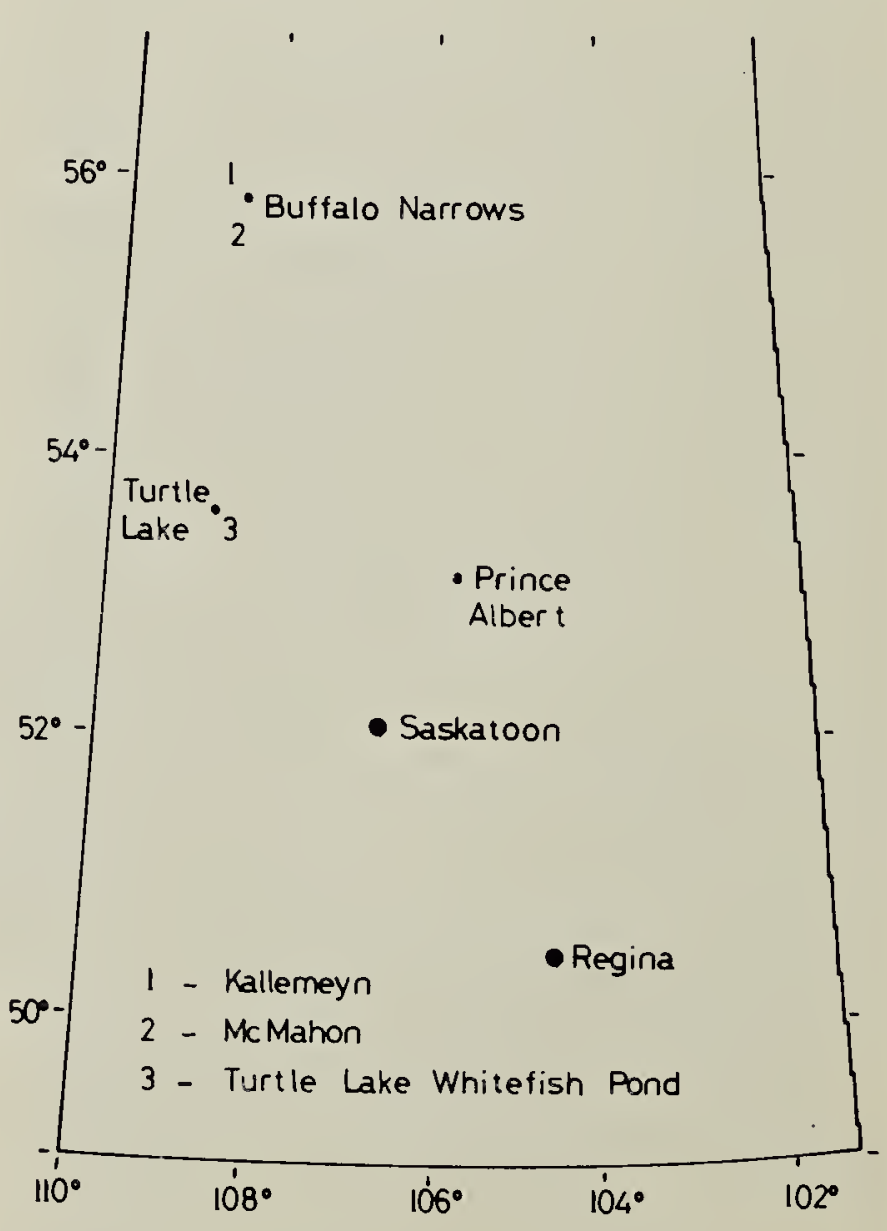

Figure 1. Location of 3 whitefish rearing ponds in Saskatchewan. 


\section{Stocking of Fry}

Whitefish fry from the Qu'Appelle Fish Culture Station were stocked into all three ponds on 30 April 1981. In 1982. Kallemeyn Pond only was stocked on 6 May. Stocking into the two northern ponds was done through ice, as the ponds were still covered with ice then. The rate of stocking (no. fry/ha) for each pond was as follows: Kallemeyn Pond, 600 in 1981, 3000 in 1982; McMahon Pond (1981), 400; Turtle Lake Pond (1981), 17,000.

\section{Food of Fingerlings}

What the fingerlings ate in these ponds appeared to be dependent on the availability and size of the food organisms, as well as on the size of the fingerlings. In general, amphipods, cladocerans and chironomid larvae were the most frequently consumed food items, while organisms such as mayfly larvae, water boatmen, caddisfly larvae, sphaeriids (minute clams), ostracods and water mites were only eaten by larger fingerlings. Some interesting differences in the diet of the fingerlings were observed. For example, the fry of Fathead Minnows were the most frequently consumed food item in the diet of the fingerlings from McMahon Pond. On the other hand, chaoborus larvae were a very important food source only for the fingerlings from Turtle Lake Pond.

The food conditions in the three ponds appeared to be good. At least $65 \%$ of the fingerlings examined for diet at any one time contained food in their stomachs; the average figure for each pond was: $85 \%, 97 \%$ and $93 \%$ for Kallemeyn, McMahon and Turtle Lake Pond, respectively.

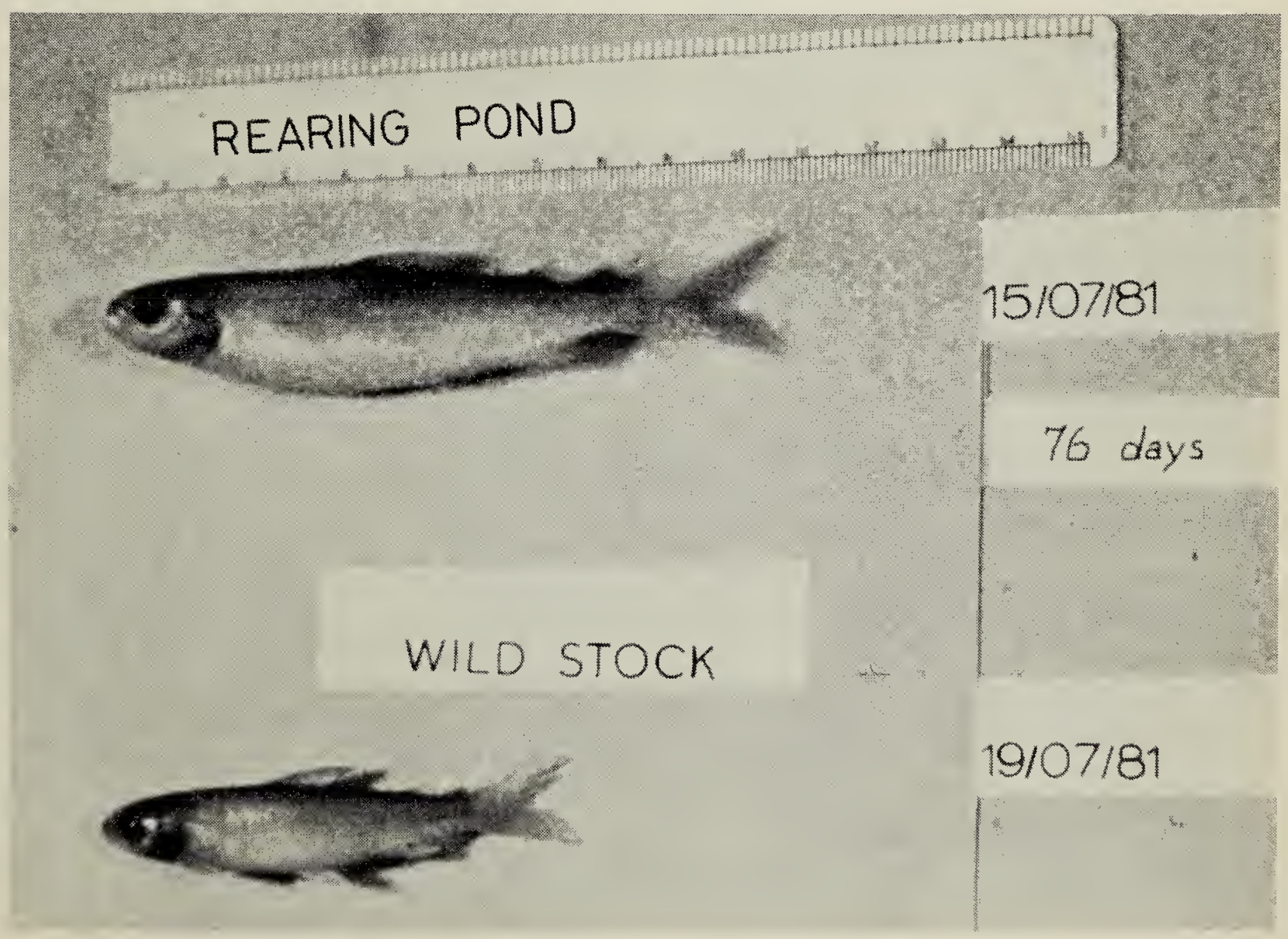

A comparison of rearing-pond grown and wild stock whitefish fingerlings. 


\section{Growth and Production}

The whitefish fingerlings in the three ponds grew fast up to about the end of August, or 90-120 days after stocking; by this time, the fingerlings could reach an average of around $142 \mathrm{~mm}$ in fork length (from nose tip to base of tail) and $42 \mathrm{~g}$ in weight. This growth was much better than that of the native whitefish fingerlings in larger lakes.

The survival of the whitefish in Turtle Lake Pond was nearly $100 \%$ up to 70 days and $30 \%$ up to 152 days after stocking. This gives a population density of 22,267 fingerlings/ha and 6,325 fingerlings/ha, respectively. At an average weight of $40 \mathrm{~g}$, the latter figure is equivalent to a production of 253 $\mathrm{kg} / \mathrm{ha}$ near the end of the summer.

A total of 13.4 thousand fingerlings were harvested from Turtle Lake Pond from 1-23 October 1981, using gillnets and trapnets. Of these, 6,050 (those caught in traps) were transferred to Turtle Lake. The intensive fishing took $88 \%$ of the fingerlings surviving at the time of harvesting.
Survival estimates from the two northern ponds are not available. However, judging from the quantities of fish taken during routine samplings, their survival was probably good. Also, no attempt was made to harvest fingerlings from these two ponds. A small fishing effort did manage to transfer about 500 fingerlings in 1981 and 1,100 in 1982 from Kallemeyn Pond to Big Peter Pond Lake.

\section{Conclusions}

This project has demonstrated that it is feasible to grow whitefish from fry to fingerlings in naturally fertile lakes in central as well as northern Saskatchewan. The survival and growth of fingerlings were good. The production from the small, fertile pond was high. However, the growth pattern suggests that there is no real advantage to keeping the fingerlings in the ponds for more than 90-120 days after stocking. Beyond this period the fingerlings increase very little in length and much less in weight and high mortalities may occur.

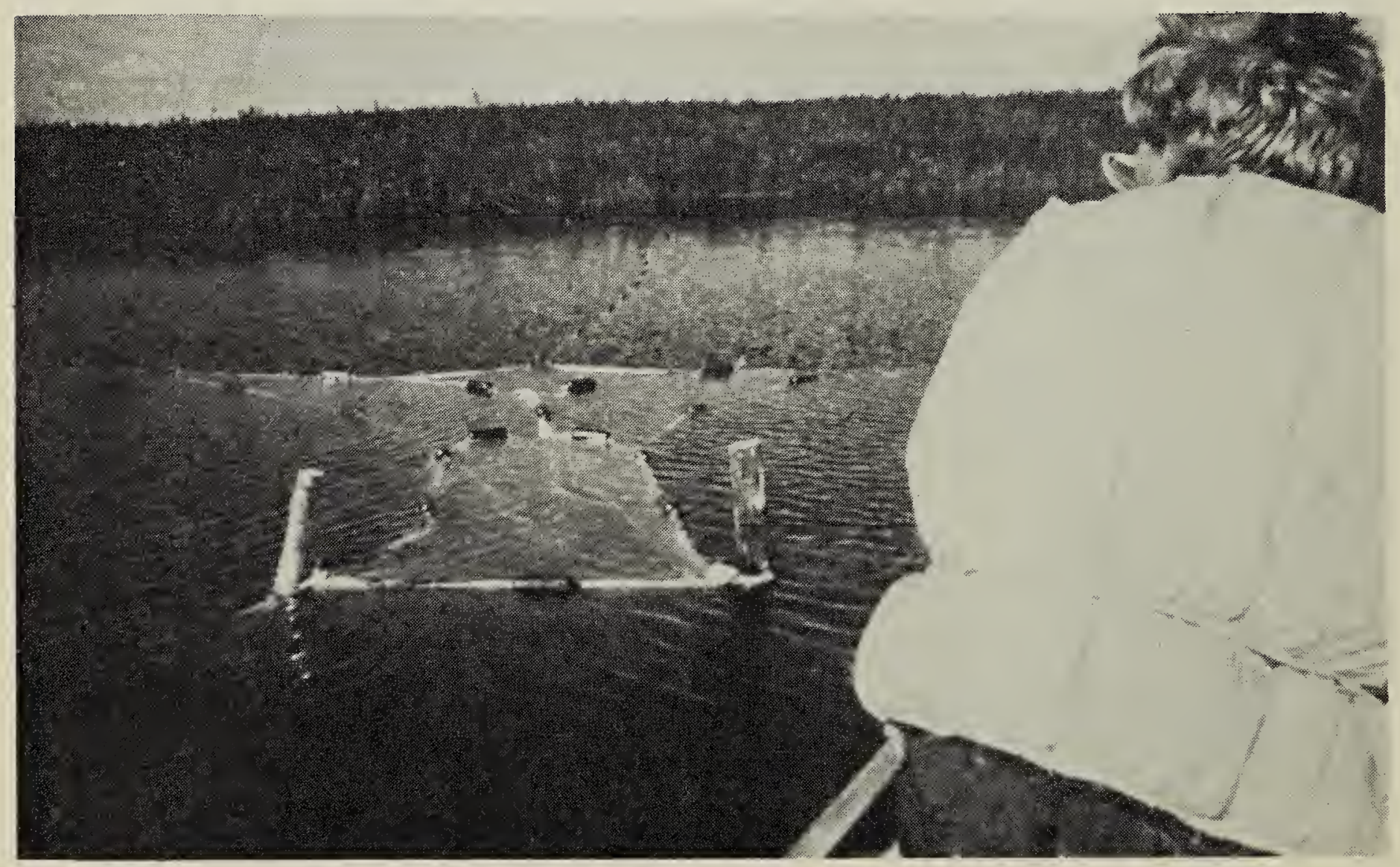

A trap net set to catch whitefish fingerlings in a rearing-pond near Buffalo Narrows. 